\title{
Compactação de biomassa vegetal visando à produção de biocombustíveis sólidos
}

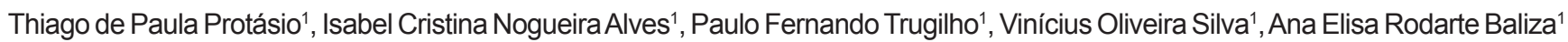

${ }^{1}$ Universidade Federal de Lavras (UFLA), Departamento de Ciências Florestais, CP 3037, CEP 37200-000 Lavras, MG, Brasil

"Autor correspondente:

depaulaprotasio@gmail.com

Termos para indexação:

Briquetes

Densidade energética

Variação volumétrica

Index terms:

Briquettes

Energetic density

Dimensional variation

Histórico do artigo:

Recebido em 09 jun 2011

Aprovado em 16 nov 2011

Publicado em 28 dez 2011

doi: 10.4336/2011.pfb.31.68.273
Resumo - O objetivo do presente trabalho foi avaliar briquetes produzidos a partir de casca de café, serragem de eucalipto e resíduos da colheita do milho, e a influência do tempo após a compactação em algumas propriedades dos briquetes. Após a biomassa ser previamente seca em estufa, os briquetes foram produzidos em uma briquetadeira laboratorial, à temperatura de $120 \pm 5^{\circ} \mathrm{C}$ e pressão de $15 \mathrm{MPa}$. Determinaram-se a densidade a granel e o poder calorífico das biomassas in natura. Após a compactação, avaliou-se a influência do tempo sobre a umidade, a expansão volumétrica e a densidade aparente dos briquetes. A partir dos resultados obtidos, pode-se observar que a casca de café moída apresentou o maior valor médio para densidade a granel. Estatisticamente, as biomassas analisadas apresentaram o mesmo poder calorífico superior. O efeito do tempo após a compactação da biomassa foi significativo para a umidade em base seca e densidade aparente para todos os briquetes produzidos. Os briquetes produzidos a partir dos resíduos da colheita do milho apresentaram acentuada expansão volumétrica. Quanto à resistência à tração por compressão diametral, os briquetes de casca de café apresentaram o maior valor. Os resultados encontrados reforçam a potencialidade de utilização energética dos briquetes oriundos da compactação da casca de café.

\section{Compaction of plant biomass for solid biofuels production}

\begin{abstract}
This research aimed to evaluate briquettes made from coffee husk, eucalyptus sawdust and maize harvesting residues, and the influence of post compaction interval on some properties of the briquettes. After oven drying of the biomass, the briquettes were produced in a laboratory briquetting machine at $120^{\circ} \mathrm{C}$ and $15 \mathrm{MPa}$. Bulk density and heating value of the fresh biomass were analyzed. After compaction, influence of time on moisture content, volumetric expansion an bulk density of the briquettes was analyzed. From the results, it was observed that milled coffee husk had the highest mean value of bulk density. There was no statistical difference for higher heating value among the biomass analyzed. The effect of pos compaction interval was significant on moisture content based on dry mass and bulk density for all briquettes produced. The briquettes produced from maize harvesting residues had high volumetric expansion. Considering tensile strength by diametric compression, coffee husk briquettes were more resistant. The results highlight the potential of energetic use of briquettes obtained by compaction of coffee husks.
\end{abstract}




\section{Introdução}

Segundo dados do Balanço Energético Nacional de 2010 , referente a 2009, aproximadamente $47 \%$ da energia interna do Brasil são provenientes de fontes renováveis, dos quais 30\% correspondiam à energia proveniente da biomassa (Empresa de Pesquisa Energética, 2010).

Devido à crescente preocupação mundial de aumentar o uso de energia de fontes renováveis, os resíduos das mais variadas origens despontam-se como interessantes alternativas energéticas. Nogueira \& Lora (2003) ressaltam que no contexto histórico e pela aparente modernidade das fontes de energia fósseis, a energia oriunda da biomassa vegetal é vista, às vezes, como superada, à espera de alternativas modernas. Entretanto, conforme relatam os autores, esta é uma visão equivocada, uma vez que nos dias atuais existem estudos visando aprimorar a qualidade e seleção da matériaprima e as técnicas para o uso da biomassa energética (Lima et al., 2011; Paula et al., 2011a; Protásio et al., 2011; Furtado et al., 2010; Botrel et al., 2007; Rabier et al., 2006; Trugilho et al., 2005; Granada et al., 2002; Trugilho et al., 2001; Chin \& Siddiqui, 2000; Demirbas, 1999; Rubio et al., 1999).

O Brasil produz grandes quantidades de resíduos oriundos da biomassa vegetal, atingindo valores em torno de 250 milhões de toneladas anuais (Quirino et al., 2004). Dessa forma, há no país grande produção de resíduos provenientes da biomassa florestal e agrícola que podem ser prejudiciais ao meio ambiente, podendo assorear e poluir os cursos d'água, ocupar extensos espaços nas indústrias e poluir o ar por meio de sua queima inadequada. Granada et al. (2002) afirmam que $20 \%$ a $30 \%$ de toda a matéria-prima utilizada nas indústrias de primeira e segunda transformação da madeira são convertidos em resíduos, tornando-se necessário o desenvolvimento de estudos que visam ao aproveitamento dessa biomassa residual.

Segundo Granada et al. (2002), a briquetagem de biomassa é um processo de densificação que melhora as características da biomassa residual, ou seja, proporciona um aumento da densidade energética, reduz custos com transporte e produz um combustível uniforme. O processo de briquetagem consiste na aplicação de pressão a uma massa de partículas, com ou sem adição de ligante, e com ou sem tratamento térmico posterior (Quirino \& Brito, 1991). Entretanto, para a produção de briquetes utilizando-se resíduos lignocelulósicos, é necessário o conhecimento sobre o processo e a qualidade final do produto obtido, que pode ser avaliada por meio da caracterização física, química e mecânica.

A densidade energética é uma importante propriedade a ser avaliada nos combustíveis de biomassa, bem como a quantidade de água presente. A umidade do combustível é a principal responsável pela redução do seu poder calorífico, pois a etapa de secagem é onde ocorre o maior consumo de energia, devido à evaporação da água. A densidade aparente também deve ser considerada na avaliação da biomassa para a produção de bioenergia, pois maiores densidades indicam mais massa disponível para um mesmo volume considerado e maior densidade energética (Brand, 2010).

Outra propriedade relevante para a caracterização dos briquetes é relativo ao seu comportamento dimensional. Esta característica física é de grande importância, pois está diretamente relacionada à estabilidade $\mathrm{e}$ integridade dos briquetes durante o transporte da fábrica até o consumidor final. Contudo, existe uma ausência na literatura de trabalhos relacionados à avaliação dimensional dos briquetes após a compactação. Assim como a estabilidade, outra característica que deve ser avaliada é a resistência à compressão diametral dos briquetes, pois caso a resistência mecânica dos briquetes não atinja valores adequados, podem ocorrer rupturas e levar à abrasão. Diante disso, a avaliação mecânica dos briquetes pode ser usada como ferramenta para direcionar seus usos, quer seja domésticos ou até mesmo aplicações em altos fornos industriais.

Os objetivos do presente trabalho foram avaliar os briquetes produzidos com resíduos lignocelulósicos, verificar a influência do tempo após a compactação em algumas propriedades dos briquetes e estimar o aumento na densidade aparente e energética da biomassa antes e após a compactação.

\section{Material e métodos}

\section{Resíduos lignocelulósicos utilizados}

Foram utilizados três tipos de biomassa vegetal: resíduos do processamento dos grãos de café (casca) da variedade Icatu (Coffea arabica L.), serragem de eucalipto (Eucalyptus spp.) e resíduos da colheita do milho (Zea mays L.) (palha, sabugo, caule e folhas). $\mathrm{Na}$ casca de café havia pequenas quantidades de pergaminho, devido ao caráter residual dessa biomassa.

A casca de café e os resíduos da colheita do milho foram moídos em um moinho martelo e classificados 
quanto à granulometria em peneiras de 40, 60 e 270 Mesh (American Society for Testing and Materials, 2001). O mesmo procedimento de classificação granulométrica foi adotado para a serragem de eucalipto.

\section{Ensaios e briquetagem dos resíduos lignocelulósicos}

Para a determinação da densidade a granel da biomassa tomou-se como base o material absolutamente seco em estufa à temperatura de $103 \pm 2{ }^{\circ} \mathrm{C}$. Foram constituídas amostras de $500 \mathrm{~cm}^{3}$ com quatro repetições de cada material. Por meio de uma balança analítica com precisão de $5 \mathrm{mg}$, determinou-se a massa acondicionada no volume de cada amostra. A densidade a granel da biomassa foi obtida dividindo-se a massa seca pelo volume da amostra. Este procedimento foi realizado para a casca de café e resíduos da colheita do milho antes e após a redução granulométrica, bem como para a serragem do eucalipto.

Para a quantificação do poder calorífico superior (PCS) da biomassa vegetal foi utilizado um calorímetro digital, sendo o ensaio padronizado com base na norma ABNT NBR 8633 (Associação Brasileira de Normas Técnicas, 1984). As amostras foram classificadas em peneiras de 40/60 Mesh (American Society for Testing and Materials, 2001). Para a determinação do poder calorífico superior, as frações das amostras retidas na peneira de 60 Mesh foram secas em estufa a $103 \pm 2{ }^{\circ} \mathrm{C}$ até massa constante.

A compactação da biomassa foi realizada em briquetadeira hidráulica. A biomassa foi previamente seca em estufa a $103 \pm 2{ }^{\circ} \mathrm{C}$. A temperatura utilizada na compactação foi de $120 \pm 5{ }^{\circ} \mathrm{C}$ e pressão de $15 \mathrm{MPa}$, conforme recomendações de Paula et al. (2011a). Os briquetes foram produzidos com diâmetro de aproximadamente $30 \mathrm{~mm}$ e altura de $60 \mathrm{~mm}$ a $70 \mathrm{~mm}$.

A densidade aparente dos briquetes foi determinada utilizando-se o método estereométrico, sendo o volume calculado considerando-se a forma cilíndrica dos briquetes. A massa foi obtida com o uso de balança analítica com precisão de $5 \mathrm{mg}$.

A densidade energética da biomassa foi calculada multiplicando-se o poder calorífico superior pela densidade a granel. Já para o cálculo da densidade energética dos briquetes, foi considerada a densidade aparente 144 horas após a compactação (devido à estabilização da densidade) e o poder calorífico superior mensurado para os resíduos lignocelulósicos.

Avaliou-se a resistência à tração por compressão diametral dos briquetes segundo as diretrizes da norma
NBR 7222 (Associação Brasileira de Normas Técnicas, 1994), com algumas adaptações. Além disso, avaliouse a força máxima suportada pelos corpos de prova. Os briquetes foram mantidos em câmara climatizada até massa constante. $\mathrm{O}$ ensaio foi realizado na Máquina de Ensaio Universal EMIC, modelo DL30000, sendo utilizada uma célula de carga com capacidade para 500 $\mathrm{Kg}$. A velocidade de ensaio foi de $0,3 \mathrm{~mm} \mathrm{~s}^{-1}$.

\section{Estabilidade dimensional}

Imediatamente após a compactação, os briquetes foram mantidos em câmara climatizada à temperatura de $23 \pm 2{ }^{\circ} \mathrm{C}$ e umidade relativa do ar de $60 \pm 5 \%$. Avaliaramse a estabilidade dimensional e as variações na densidade aparente e na umidade em base seca dos briquetes durante sete dias consecutivos, após a compactação da biomassa.

Para a realização das análises, os diâmetros dos briquetes foram determinados pela média das medidas da parte superior, inferior e do centro dos corpos-deprova, realizadas com paquímetro digital com precisão de $0,01 \mathrm{~mm}$.

A expansão volumétrica foi determinada por meio da Equação 1.

$$
\operatorname{Exp}=\left(\mathrm{Vol}_{2}-\mathrm{Vol}_{1}\right) / \mathrm{Vol}_{1} \text { x } 100
$$

Em que: Exp é a expansão volumétrica dos briquetes (\%); Vol é o volume do briquete imediatamente após a compactação $\left(\mathrm{cm}^{3}\right)$; $\mathrm{Vol}_{2}$ é volume do briquete transcorrido certo tempo após a compactação $\left(\mathrm{cm}^{3}\right)$.

\section{Análises estatísticas}

$\mathrm{Na}$ avaliação da expansão volumétrica (em horas) dos briquetes utilizou-se o esquema fatorial $3 \times 6$, ou seja, três tipos de briquetes e seis tempos após a compactação da biomassa e o esquema fatorial $3 \times 7$ para umidade e densidade aparente, com 20 repetições, conforme modelo estatístico apresentado na Equação 2. Para o fator qualitativo (tipo de briquete), utilizou-se o Teste de Tukey em nível de 5\% de significância para a comparação múltipla das médias. Para verificação do efeito do tempo após a compactação na variação volumétrica, densidade aparente e umidade dos briquetes, utilizou-se a análise de regressão por meio do ajuste de modelos estatísticos polinomiais de segundo e terceiro graus.

$$
\mathrm{Y}_{\mathrm{ijk}}=\mu+\tau_{\mathrm{i}}+\beta_{\mathrm{j}}+(\tau \beta)_{\mathrm{ij}}+\varepsilon_{\mathrm{ijk}}
$$

Em que: $Y_{\mathrm{ijk}}$ é o efeito do $i$-ésimo nível do fator tipo de briquete ( $i=1,2$ e 3 ), no $j$-ésimo nível do fator tempo após a compactação $(\mathrm{j}=1,2, \ldots, 6$ ou 7) na $k$-ésima repetição $(\mathrm{k}=1,2, \ldots, 20) ; \mu$ é uma constante inerente a 
todas as observações; $\tau_{\mathrm{i}}$ é o efeito do $i$-ésimo nível do fator tipo de briquete $(i=1,2$ e 3$)$, efeito fixo; $\beta_{\mathrm{j}}$ é o efeito do $j$-ésimo nível do fator tempo após a compactação $(\mathrm{j}=$ $1,2, \ldots, 6$ ou 7), efeito fixo; $(\tau \beta)_{\mathrm{ij}}$ é o efeito da interação (efeito aleatório) e $\varepsilon_{\mathrm{ijk}}$ é o erro experimental associado à observação $\mathrm{Y}_{\mathrm{ijk}}$, independente e identicamente distribuído de uma distribuição Normal.

$\mathrm{Na}$ avaliação dos briquetes quanto à resistência à tração por compreensão diametral e força máxima, utilizou-se o delineamento inteiramente casualizado, considerando-se dez repetições, conforme a Equação 3. Para a comparação múltipla das médias utilizou-se o Teste de Tukey em nível de 5\% de significância.

$$
\mathrm{Y}_{\mathrm{ij}}=\mu+\tau_{\mathrm{i}}+\varepsilon_{\mathrm{ij}}
$$

Em que: $Y_{i j}$ é a observação do i-ésimo tipo de briquete $(i=1,2$ e 3$)$ na j-ésima repetição $(j=1,2,3, \ldots, 10) ; \mu$ é uma constante inerente a todas as observações; $t_{i}$ é o efeito do i-ésimo tipo de briquete $(\mathrm{i}=1,2$ e 3$)$; $\varepsilon_{\mathrm{ij}}$ é o erro experimental associado à observação $\mathrm{Y}_{\mathrm{ij}}$, independente $\mathrm{e}$ identicamente distribuído de uma distribuição Normal.

Para o poder calorífico superior, considerou-se o modelo estatístico apresentado na Equação 3 com os seguintes tratamentos: serragem de eucalipto, casca de café e resíduos da colheita do milho e quatro repetições. De forma semelhante, para densidade a granel da biomassa, considerou-se o delineamento inteiramente casualizado com cinco tratamentos: casca de café, moída e não moída, resíduos moídos e não moídos da colheita do milho e serragem de eucalipto. Para a comparação múltipla utilizou-se o Teste de Tukey em nível de 5\% de significância.

\section{Resultados e discussão}

\section{Resíduos lignocelulósicos utilizados}

A classificação granulométrica da biomassa avaliada encontra-se na Figura 1.

Observa-se que após moagem no moinho martelo a casca de café apresentou maior granulometria que os outros materiais, sendo composta por aproximadamente $84 \%$ de partículas com diâmetros iguais ou superiores a $0,42 \mathrm{~mm}$, as quais ficaram retidas na peneira de 40 Mesh, $11 \%$ de partículas com diâmetros iguais ou superiores a 0,25 mm, retidas na peneira de 60 Mesh e o restante com fração menor ou igual a $0,053 \mathrm{~mm}$ de diâmetro( $\leq 270 \mathrm{Mesh}$ ). Já a serragem de eucalipto apresentou menor porcentagem de partículas retidas na peneira de $40 \mathrm{Mesh}$, devido à maior quantidade de partículas retidas nas peneiras de 60 Mesh e 270 Mesh. Os resíduos da colheita do milho apresentaram após a moagem partículas com frações intermediárias, sendo encontrados aproximadamente $69 \%$ de fração composta por partículas retidas na peneira de $40 \mathrm{Mesh}, 20 \%$ na de 60 Mesh e o restante (11\%) com dimensões menores ou iguais àquelas apresentadas pela peneira de $270 \mathrm{Mesh}$.

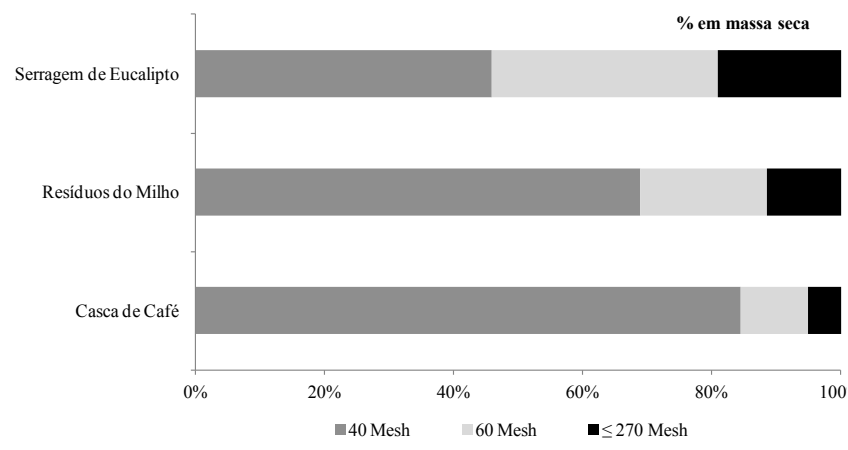

Figura 1. Classificação granulométrica da biomassa de serragem de eucalipto, casca de café e resíduos da cultura do milho.

As diferenças na granulometria da biomassa após a trituração devem-se provavelmente às características iniciais (naturais/estruturais) dos resíduos. Provavelmente, aqueles que apresentaram menor resistência à trituração produziram frações com menores granulometrias, o que poderá influenciar a densidade aparente da biomassa e dos briquetes produzidos. Segundo Kaliyan \& Morey (2009), o tamanho das partículas é um influenciador importante da durabilidade e resistência dos briquetes, evidenciando a importância da classificação granulométrica da biomassa antes da compactação.

\section{Avaliação energética e física dos resíduos lignocelulósicos e dos briquetes}

Os valores médios obtidos para a densidade a granel da biomassa utilizada na produção dos briquetes, além do teste de comparação múltipla realizado, estão apresentados na Figura 2. 


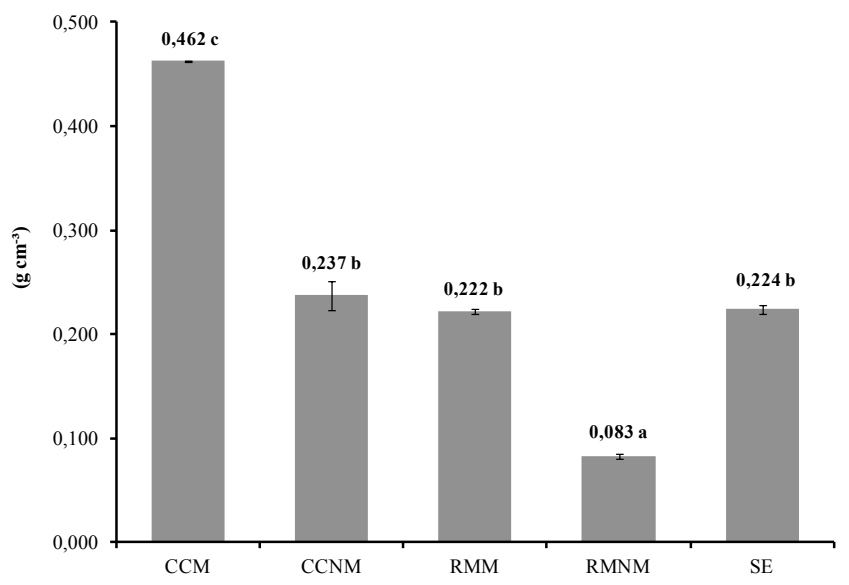

Figura 2. Densidade a granel média da biomassa vegetal analisada. CCM: casca de café moída; CCNM: casca de café não moída; RMM: resíduos moídos da colheita do milho; RMNM: resíduos da colheita do milho não moídos; SE: serragem de eucalipto. Médias seguidas pela mesma letra não diferem entre si a 5\% de significância pelo Teste de Tukey.

É desejável que os resíduos lignocelulósicos apresentem maiores valores de densidade a granel, pois fatores como os custos com transporte e a densidade energética são essenciais na viabilidade econômica das energias renováveis. Observou-se que o efeito dos resíduos lignocelulósicos foi significativo a $1 \%$ de probabilidade pelo teste $\mathrm{F}$ para a densidade a granel da biomassa. O coeficiente de variação encontrado foi de $3,36 \%$ e é um indício da alta precisão do experimento (Pimentel-Gomes, 2009).

A densidade a granel da casca de café moída apresentou o maior valor médio, sendo superior em aproximadamente $95 \%$, em relação à densidade a granel da casca de café não moída. Esse resultado poderá influenciar na qualidade do briquete produzido devido à acomodação das partículas no momento da compactação.

Os resíduos da colheita do milho não moídos apresentaram a menor densidade a granel, sendo que após a trituração das partículas houve um aumento dessa propriedade em aproximadamente $167 \%$. Observou-se ainda que a densidade a granel da casca de café não moída, dos resíduos moídos da colheita do milho e da serragem de eucalipto foram estatisticamente iguais a $5 \%$ de significância pelo Teste de Tukey. Esse resultado é um indicativo da superioridade da casca de café a granel para o aproveitamento energético.

Os valores médios e o teste de comparação múltipla para o poder calorífico superior da biomassa vegetal analisada estão apresentados na Figura 3.

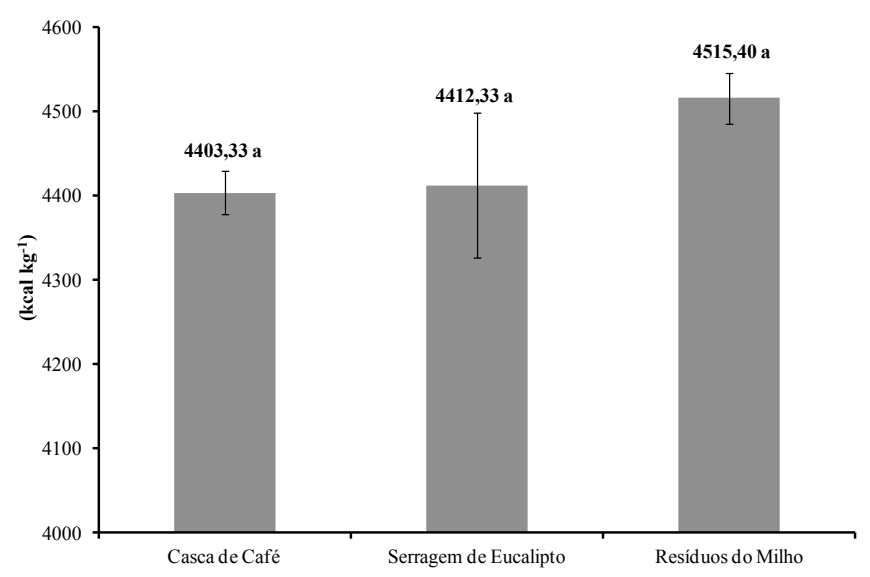

Figura 3. Poder calorífico superior médio da biomassa vegetal utilizada. Médias seguidas pela mesma letra não diferem entre si a 5\% de significância pelo Teste de Tukey.

O poder calorífico é um excelente parâmetro para se avaliar a potencialidade energética de combustíveis de biomassa (Protásio et al., 2011; Brand, 2010; Friedl et al., 2005; Parikh et al., 2005), sendo definido como a quantidade de energia liberada na combustão completa de uma unidade de massa do material combustível e apresenta significativa dependência da constituição química elementar e mineral da biomassa (Protásio et al., 2011). Observou-se que o efeito dos resíduos lignocelulósicos no poder calorífico superior foi não significativo a $5 \%$ pelo Teste $\mathrm{F}$, ou seja, as diferentes biomassas analisadas apresentaram estatisticamente $\mathrm{o}$ mesmo poder calorífico superior (em média $4.444 \mathrm{kcal}$ $\mathrm{kg}^{-1}$ ), com baixo coeficiente de variação experimental $(1,97 \%)$. Além disso, para a geração de energia são consideradas significativas diferenças superiores a $300 \mathrm{kcal} \mathrm{kg}^{-1}$ no poder calorífico nos combustíveis de biomassa (Brand, 2010).

Os resultados encontrados para o poder calorífico superior da casca de café estão próximos àqueles relatados por Paula et al. (2011b), estudando o pergaminho desse fruto.

De forma semelhante, Protásio et al. (2011) encontraram para os resíduos do processamento dos grãos de café poder calorífico superior médio de 4.606,3 kcal $\mathrm{kg}^{-1}$, diferindo apenas $4,61 \%$ do relatado nesse trabalho. Os mesmos autores encontram poder calorífico superior médio de $4.572,2 \mathrm{kcal} \mathrm{kg}^{-1}$ para maravalhas de eucalipto, assemelhando-se ao encontrado para a serragem dessa mesma biomassa.

Já o poder calorífico superior encontrado por Furtado et al. (2010), estudando diferentes tipos de resíduos de 
Pinus sp. para produção de briquetes, foi superior ao da serragem de eucalipto. Este fato pode ser explicado devido à diferença de composição química entre as espécies, especialmente quanto aos teores de extrativos e lignina, e pode ser de grande valia na seleção preliminar de combustíveis de biomassa para a geração de bioenergia.

Os valores médios encontrados para a densidade energética da biomassa vegetal antes e após a compactação estão apresentados na Figura 4.

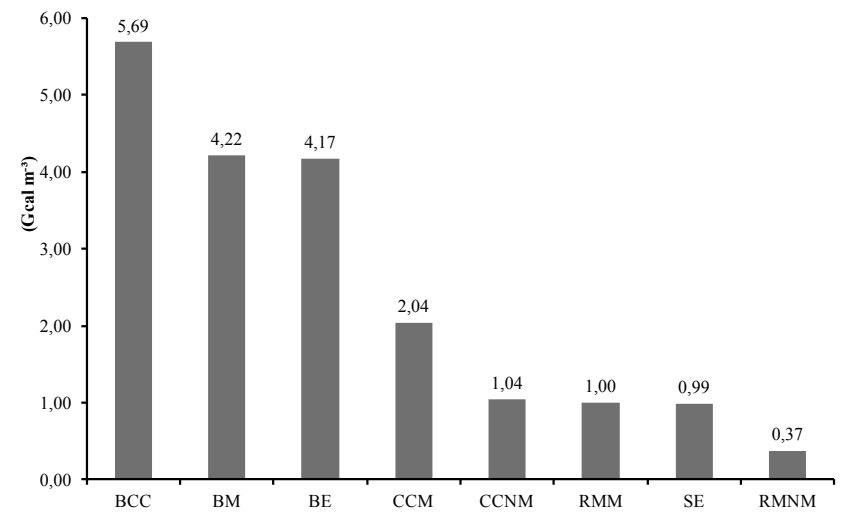

Figura 4. Densidade energética média da biomassa antes e após a compactação. BCC: briquetes de casca de café; BM: briquetes de resíduos moídos da colheita do milho; BE: briquetes de serragem de eucalipto; CCM: casca de café moída; CCNM: casca de café não moída; RMM: resíduos da colheita do milho moídos; SE: serragem de eucalipto; RMNM: resíduos da colheita do milho não moídos.

Após a compactação, observou-se um aumento de aproximadamente $179 \%, 321 \%$ e $322 \%$ na densidade energética da casca de café moída, serragem de eucalipto e resíduos da colheita do milho, respectivamente, evidenciando a importância da briquetagem no aproveitamento de resíduos lignocelulósicos para a geração de bioenergia. Se for considerada a biomassa antes e após a redução granulométrica, observou-se um aumento de $50 \%$ e $170 \%$ na densidade energética para a casca de café e resíduos da colheita do milho, respectivamente. Contudo, o aumento percentual dessa variável para a casca de café após a trituração e compactação foi menor quando comparado aos demais resíduos, uma vez que a densidade a granel da casca de café foi superior à das demais biomassas analisadas.

Observa-se que os briquetes produzidos a partir de casca de café apresentaram a maior densidade energética para as condições experimentais consideradas. Já os briquetes produzidos a partir da serragem de eucalipto e dos resíduos da colheita do milho obtiveram valores semelhantes. Os resíduos in natura apresentaram baixa densidade energética. Lima et al. (2011) encontraram densidade energética para Eucalyptus benthamii de 2,22 $\mathrm{Gcal} \mathrm{m}^{-3}$, inferior à encontrada neste trabalho para todos os briquetes produzidos. Esse resultado é um indicativo do potencial energético dos biocombustíveis sólidos analisados.

Couto et al. (2004) comentaram que a baixa densidade energética da biomassa sólida, em comparação com o petróleo e o carvão mineral, resulta em custos elevados de transporte e armazenamento. Assim, o desenvolvimento contínuo de técnicas para aumentar a concentração de energia ampliará o espectro de utilização da biomassa na transformação energética, por exemplo, a briquetagem, técnica pela qual é possível obter incrementos na densidade aparente, contribuindo de forma significativa para um aumento na quantidade de energia por unidade de volume.

\section{Estabilidade dimensional e variação da umidade e densidade dos briquetes}

Observa-se que o efeito da interação tipo de briquete $\mathrm{x}$ tempo após a compactação foi significativo para as três características mensuradas (Tabela 1). Interação significativa indica que existe dependência entre os fatores. Dessa forma, optou-se em fazer o seu desdobramento e avaliar o efeito do tipo de briquete dentro dos tempos após a compactação e vice versa. Os elevados coeficientes de variação encontrados para a expansão volumétrica e umidade dos briquetes indicam que os briquetes produzidos apresentaram alta variabilidade quanto a essas características. Contudo, o coeficiente de variação experimental para a densidade aparente dos briquetes foi baixo (Pimentel-Gomes, 2009). 
Tabela 1. Resumo das análises de variâncias realizadas para a expansão volumétrica, umidade, em base seca, e densidade aparente dos briquetes.

\begin{tabular}{cccccc}
\hline \multirow{2}{*}{ FV } & GL & $\begin{array}{c}\text { Quadrado } \\
\text { médio }\end{array}$ & & \multirow{2}{*}{ GL } & \multicolumn{2}{c}{ Quadrado médio } \\
\cline { 5 - 6 } & & Exp & & Ubs & Da \\
\hline TB & 2 & $16369,47^{*}$ & 2 & $115,74^{*}$ & $4,1413^{*}$ \\
$\mathrm{~T}$ & 5 & $1692,39^{*}$ & 6 & $353,07^{*}$ & $0,1144^{*}$ \\
TB*T & 10 & $387,84^{*}$ & 12 & $12,92^{*}$ & $0,0493^{*}$ \\
Erro & 342 & 24,71 & 399 & 1,5732 & 0,0027 \\
\hline CV (\%) & & 35,52 & & 23,71 & 4,75
\end{tabular}

FV: fator de variação; GL: graus de liberdade; TB: tipo de briquete; T: tempo após a compactação; TB*T: interação entre o tipo de briquete e o tempo após a compactação; Ubs: umidade em base seca (\%); Exp: expansão volumétrica dos briquetes (\%); Da: densidade aparente $\left(\mathrm{g} \mathrm{cm}^{-3}\right)$; $\mathrm{CV}$ : coeficiente de variação $(\%) ;$ *: significativo a $1 \%$ pelo Teste $\mathrm{F}$.

Observa-se que imediatamente após a compactação da biomassa (tempo $0 \mathrm{~h}$ ) todos os briquetes encontravamse absolutamente secos (Tabela 2). Esse resultado demonstra a influência dos demais componentes químicos da biomassa (como os extrativos e os carboidratos), bem como da granulometria no processo de briquetagem e união das partículas, uma vez que a transição vítrea da lignina in situ pode chegar a $205^{\circ} \mathrm{C}$ (Back \& Salmén, 1982). Além disso, pode ocorrer um aumento da temperatura de transição vítrea da lignina com a diminuição da umidade.

Os resíduos da colheita do milho e a casca de café apresentaram os maiores valores de umidade, em base seca, para os tempos após compactação de 24, 48, 72 e 96 horas. Contudo, para 120 e 144 horas após a compactação, todos os briquetes avaliados apresentaram estatisticamente o mesmo valor médio de umidade em base seca. Esse resultado sugere que o efeito da biomassa na umidade em base seca dos briquetes deve ser desconsiderado à medida que esses biocombustíveis sólidos atingem o equilíbrio higroscópico para as condições experimentais consideradas.
Tabela 2. Resultado do desdobramento tipo de briquete dentro de cada nível de tempo após a compactação e teste de comparação múltipla realizado para a umidade, expansão volumétrica e densidade aparente dos briquetes.

\begin{tabular}{|c|c|c|c|c|}
\hline \multirow[b]{2}{*}{ Variáveis } & \multirow{2}{*}{$\begin{array}{c}\text { Tempo } \\
\text { (h) }\end{array}$} & \multicolumn{3}{|c|}{ Tipo de briquete } \\
\hline & & $\begin{array}{l}\text { Serragem de } \\
\text { eucalipto }\end{array}$ & $\begin{array}{l}\text { Resíduos } \\
\text { de milho }\end{array}$ & $\begin{array}{l}\text { Casca } \\
\text { de café }\end{array}$ \\
\hline \multirow{7}{*}{$\begin{array}{c}\text { Umidade } \\
\text { em base seca } \\
(\%)\end{array}$} & 0 & $0,00 \mathrm{a}$ & $0,00 \mathrm{a}$ & $0,00 \mathrm{a}$ \\
\hline & 24 & $2,34 \mathrm{a}$ & $5,66 \mathrm{~b}$ & $6,24 \mathrm{~b}$ \\
\hline & 48 & $4,90 \mathrm{a}$ & $6,52 \mathrm{~b}$ & $6,77 \mathrm{~b}$ \\
\hline & 72 & $4,47 \mathrm{a}$ & $6,97 \mathrm{~b}$ & $7,86 \mathrm{~b}$ \\
\hline & 96 & $5,49 \mathrm{a}$ & $6,87 \mathrm{~b}$ & $7,25 \mathrm{~b}$ \\
\hline & 120 & $6,25 \mathrm{a}$ & $6,71 \mathrm{a}$ & $6,95 \mathrm{a}$ \\
\hline & 144 & $6,29 \mathrm{a}$ & $6,52 \mathrm{a}$ & $7,02 \mathrm{a}$ \\
\hline \multirow{6}{*}{$\begin{array}{c}\text { Expansão } \\
\text { volumétrica } \\
(\%)\end{array}$} & 24 & $5,07 \mathrm{~b}$ & $10,05 \mathrm{c}$ & $0,71 \mathrm{a}$ \\
\hline & 48 & $12,01 \mathrm{~b}$ & $18,35 \mathrm{c}$ & $0,97 \mathrm{a}$ \\
\hline & 72 & $15,59 \mathrm{~b}$ & $25,26 \mathrm{c}$ & $1,66 \mathrm{a}$ \\
\hline & 96 & $18,68 \mathrm{~b}$ & $28,54 \mathrm{c}$ & $2,24 \mathrm{a}$ \\
\hline & 120 & $19,10 \mathrm{~b}$ & $33,15 \mathrm{c}$ & $2,43 \mathrm{a}$ \\
\hline & 144 & $19,68 \mathrm{~b}$ & $35,35 \mathrm{c}$ & $2,96 \mathrm{a}$ \\
\hline \multirow{7}{*}{$\begin{array}{l}\text { Densidade } \\
\text { aparente } \\
\left(\mathrm{g} \mathrm{cm}^{-3}\right)\end{array}$} & 0 & $1,060 \mathrm{a}$ & $1,159 \mathrm{~b}$ & $1,248 \mathrm{c}$ \\
\hline & 24 & $1,034 \mathrm{a}$ & $1,114 \mathrm{~b}$ & $1,332 \mathrm{c}$ \\
\hline & 48 & $0,989 \mathrm{a}$ & $1,048 \mathrm{~b}$ & $1,318 \mathrm{c}$ \\
\hline & 72 & $0,962 \mathrm{a}$ & $1,001 \mathrm{a}$ & $1,313 \mathrm{~b}$ \\
\hline & 96 & $0,946 \mathrm{a}$ & $0,970 \mathrm{a}$ & $1,305 \mathrm{~b}$ \\
\hline & 120 & $0,950 \mathrm{a}$ & $0,934 \mathrm{a}$ & $1,287 \mathrm{~b}$ \\
\hline & 144 & $0,946 \mathrm{a}$ & $0,934 \mathrm{a}$ & $1,291 \mathrm{~b}$ \\
\hline
\end{tabular}

Médias seguidas pela mesma letra na linha não diferem entre si a $5 \%$ de significância pelo Teste de Tukey.

O efeito do tipo de briquete dentro de cada nível de tempo para a expansão volumétrica e densidade aparente dos briquetes foi significativo para todos os níveis avaliados. Observa-se que os briquetes de resíduos da colheita de milho apresentaram os maiores valores médios de expansão volumétrica e os briquetes de casca de café os menores. Os briquetes de serragem de eucalipto apresentaram-se intermediários quanto a essa característica. Dessa forma, os briquetes produzidos a partir dos resíduos da colheita do milho apresentaram restrições à utilização energética, pois variações volumétricas elevadas nos briquetes poderão contribuir para uma diminuição nas propriedades de resistência mecânica e diminuição da densidade aparente e energética desses biocombustíveis sólidos. 
Quanto à densidade aparente dos briquetes, observase que para os tempos 0,24 e 48 horas após a compactação todos os briquetes apresentaram valores médios diferentes estatisticamente, sendo que os briquetes da serragem da madeira de eucalipto e casca de café apresentaram as menores e maiores médias, respectivamente. Resultado diferente foi observado nos tempos de 72, 96, 120 e 144 horas após a compactação, em que os briquetes de serragem do eucalipto e dos resíduos do milho apresentaram estatisticamente os menores valores médios.

Esse resultado sugere que, na avaliação de briquetes para a produção de bioenergia, é imprescindível a avaliação da variação da densidade aparente após a compactação da biomassa, pois uma diminuição da densidade aparente dos briquetes pode elevar os custos de transporte além de acarretar uma diminuição na densidade energética. A densidade aparente dos briquetes de casca de café está próxima à determinada por Furtado et al. (2010) para diferentes matérias-primas e pressões de compactação.

Observou-se ainda um aumento de aproximadamente $321 \%$ da densidade dos resíduos do milho se for considerada a biomassa moída antes e após a compactação no tempo $144 \mathrm{~h}$. Já a biomassa de eucalipto apresentou um aumento de $322 \%$ e a casca de café moída um acréscimo de $179 \%$ na densidade. Esses resultados indicam que, quanto menor a densidade da biomassa a granel, maior será o aumento percentual da sua densidade após a compactação e melhor será a acomodação das partículas, corroborando com os resultados da pesquisa de Iwakiri et al. (2008) para painéis de madeira.

Avaliando-se o desdobramento do tempo após a compactação da biomassa dentro de cada nível do fator tipo de briquete, observou-se efeito significativo para a umidade em base seca e densidade aparente para todos os briquetes produzidos ( $\mathrm{p}$-valor $<0,05$ ). Contudo, o efeito do tempo após a compactação da biomassa na expansão volumétrica dos briquetes de casca de café foi não significativo ( $p$-valor $>0,05$ ). Esse resultado sugere que, com vistas à produção energética, os briquetes de casca de café apresentaram melhores resultados, pois estatisticamente não apresentaram variação volumétrica após a compactação da biomassa. Além disso, apresentaram elevada densidade aparente e, consequentemente, elevada densidade energética.

Observa-se que a variação da umidade, em função do tempo após a compactação, foi explicada por modelos polinomiais de terceiro grau para os briquetes produzidos com base nos três materiais lignocelulósicos. As equações ajustadas foram significativas e os coeficientes de determinação encontrados podem ser considerados satisfatórios (Tabela 3).

Tabela 3. Parâmetros dos modelos polinomiais ajustados para a umidade em base seca, expansão volumétrica e densidade aparente dos briquetes em função do tempo após a compactação.

\begin{tabular}{|c|c|c|c|c|c|c|c|}
\hline \multirow{2}{*}{ Var } & \multirow{2}{*}{ TB } & \multicolumn{4}{|c|}{ Parâmetros dos modelos ajustados } & \multirow{2}{*}{ p-valor ${ }^{1}$} & \multirow{2}{*}{$\mathbf{R}^{2}$} \\
\hline & & $\beta_{0}$ & $\beta_{1}$ & $\boldsymbol{\beta}_{2}$ & $\boldsymbol{\beta}_{3}$ & & \\
\hline \multirow{3}{*}{ Ubs } & $\mathrm{BCC}$ & 0,397095 & 0,268364 & $-0,003204$ & 0,000011 & $0,0000^{*}$ & 0,94 \\
\hline & $\mathrm{BE}$ & $-0,020548$ & 0,134643 & $-0,001145$ & 0,000004 & $0,0000^{*}$ & 0,97 \\
\hline & $\mathrm{BM}$ & 0,184774 & 0,271712 & $-0,003073$ & 0,000011 & $0,0000^{*}$ & 0,98 \\
\hline \multirow{3}{*}{ Exp } & $\mathrm{BCC}$ & - & - & - & - & $0,6821^{\mathrm{ns}}$ & - \\
\hline & $\mathrm{BE}$ & $-2,101950$ & 0,347462 & $-0,001380$ & - & $0,0000^{*}$ & 0,99 \\
\hline & $\mathrm{BM}$ & 1,090800 & 0,413973 & $-0,001230$ & - & $0,0000^{*}$ & 0,99 \\
\hline \multirow{3}{*}{ DA } & $\mathrm{BCC}$ & 1,271125 & 0,001306 & $-0,000009$ & - & $0,0000^{*}$ & 0,49 \\
\hline & $\mathrm{BE}$ & 1,065492 & $-0,001945$ & 0,000008 & - & $0,0000^{*}$ & 0,98 \\
\hline & $\mathrm{BM}$ & 1,166546 & $-0,002866$ & 0,000008 & - & $0,0000^{*}$ & 0,99 \\
\hline
\end{tabular}

${ }^{1}$ Referente ao desdobramento do tempo dentro de cada nível do fato tipo de briquete. Var: variáveis; Ubs: umidade em base seca (\%); Exp: expansão volumétrica dos briquetes (\%); DA: densidade aparente $\left(\mathrm{g} \mathrm{cm}^{-3}\right)$; TB: tipo de briquete; BCC: briquetes de casca de café moída; BE: briquetes de serragem de eucalipto; BM: briquetes de resíduos moídos da colheita do milho; $\mathrm{R}^{2}$ : coeficiente de determinação; ${ }^{*}$ : significativo a $1 \%$ pelo Teste $\mathrm{F}$; ns: não significativo a $5 \%$ pelo Teste $\mathrm{F}$. 
Esses resultados indicam a significativa influência do tempo na umidade dos briquetes, nas condições experimentais consideradas. Já o efeito do tempo após a compactação da biomassa na expansão volumétrica dos briquetes de serragem de eucalipto e resíduos da colheita do milho foi explicado por modelos polinomiais de segundo grau.

Quanto aos briquetes de casca de café, não foi possível efetuar o ajuste de um modelo estatístico, pois não foi constatado efeito significativo do tempo na expansão volumétrica desse material. Esse resultado é um indicativo da presença de fortes ligações mecânicas e químicas entre as partículas de casca de café moída após a compactação da biomassa. Possivelmente, a lignina e demais componentes químicos (como os extrativos) presentes na casca de café atuaram como um aglutinante ou agente termoplástico (Granada et al., 2002), aumentando a força de ligação química entre as partículas e proporcionando ao briquete menor variação volumétrica.

Quanto à densidade aparente dos briquetes de casca de café, pode-se observar que o modelo polinomial quadrático não foi adequado para explicar o efeito do tempo após a compactação da biomassa. Isso ocorreu devido à baixa variação da densidade aparente desses briquetes e é um indicativo da alta estabilidade desses biocombustíveis produzidos a partir da compactação desse tipo de material. Já para os briquetes de serragem de eucalipto e resíduos da colheita do milho, os modelos polinomiais de segundo grau foram eficientes para representar o efeito do tempo após a compactação da biomassa na densidade aparente desses biocombustíveis sólidos.

Observa-se que os briquetes de casca de café moída apresentaram umidade em base seca mais elevada 24 horas após a briquetagem, tendendo a estabilizar a partir de 72 horas, apresentando ligeiro decréscimo em 120 horas (Figura 5).

Os briquetes produzidos a partir dos resíduos da colheita do milho apresentaram comportamento similar aos de casca de café. Já os briquetes de serragem de eucalipto apresentaram aumento da umidade em base seca até 96 h, assemelhando-se a partir daí aos demais briquetes produzidos.

Observou-se um acentuado aumento da expansão volumétrica dos briquetes produzidos a partir dos resíduos da colheita do milho, evidenciando alta instabilidade dimensional desse material (Figura 6).
Pode-se observar a baixa variação na densidade aparente dos briquetes de casca de café após a compactação da biomassa e, consequentemente, baixo ajuste do modelo polinomial de segundo grau (Figura 7).

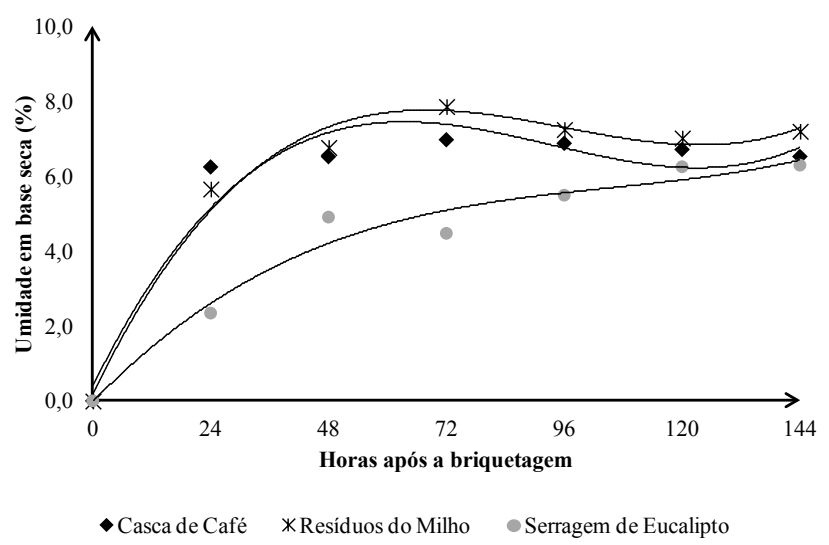

Figura 5. Umidade em base seca dos briquetes após a compactação.

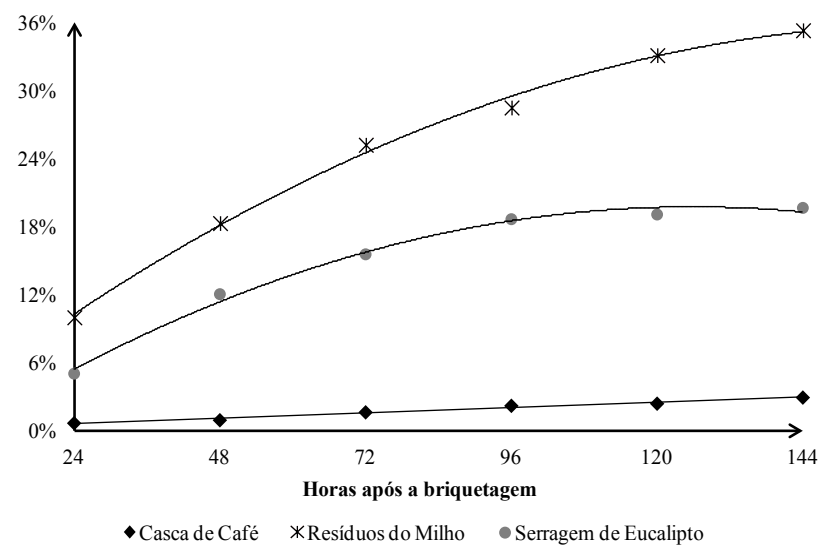

Figura 6. Expansão volumétrica dos briquetes após a compactação.

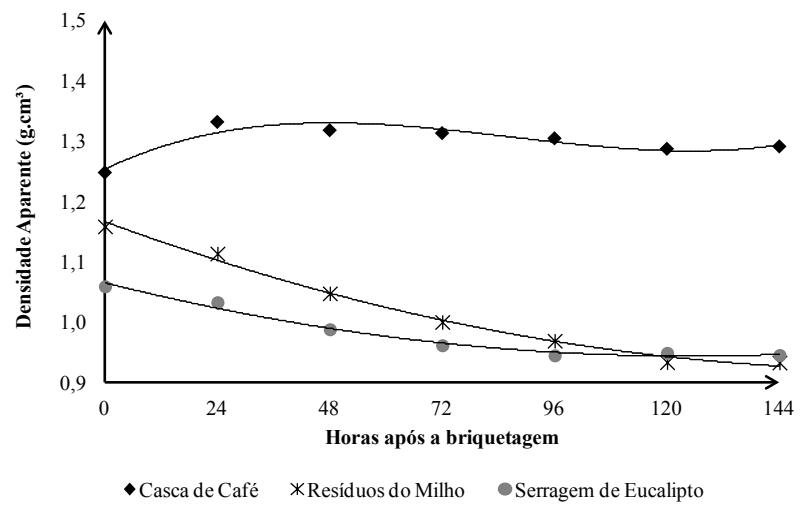

Figura 7. Densidade aparente dos briquetes após a compactação. 
Já os briquetes de serragem de eucalipto e dos resíduos da colheita do milho apresentaram um decréscimo da densidade aparente até 72 horas após a briquetagem, tendendo a estabilizar a partir daí até 144 horas. Observa-se ainda que o decréscimo da densidade aparente dos briquetes oriundos da colheita do milho foi mais acentuado em relação aos briquetes de serragem de eucalipto. Isso ocorreu provavelmente devido à elevada variação volumétrica desses briquetes, o que pode dificultar a utilização energética desses materiais.

\section{Ensaio mecânico}

$\mathrm{Na}$ avaliação dos briquetes quanto à resistência à tração por compressão diametral e força máxima obtida no ensaio, observou-se que o efeito do tipo de briquete foi significativo ( $\mathrm{p}$-valor $<0,05$ ) para essas propriedades. Os coeficientes de variação obtidos foram de $19,27 \%$ e $17,22 \%$, respectivamente.

Observa-se que os briquetes de casca de café apresentaram estatisticamente a maior resistência à tração por compressão diametral e força máxima (Figura 8). Esse resultado deve-se provavelmente à maior densidade aparente observada para esses briquetes (Paula et al., 2011a), à baixa expansão volumétrica e à baixa variação da densidade aparente após a compactação da biomassa utilizada.

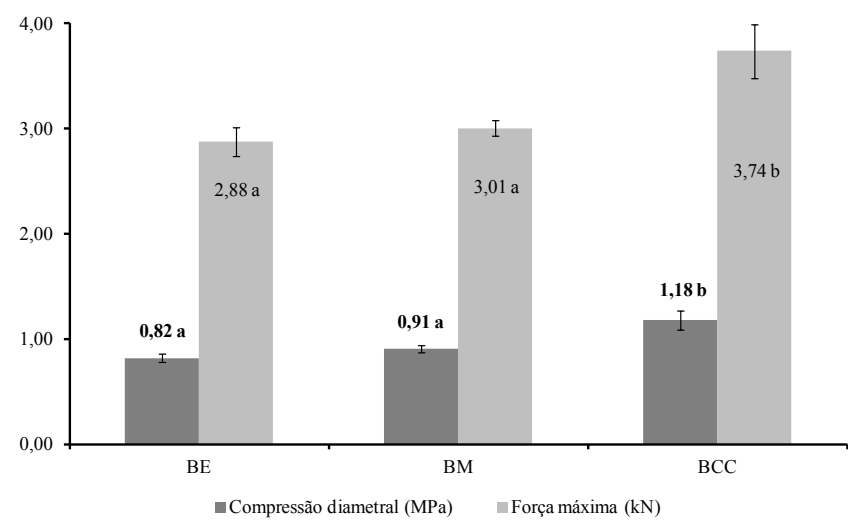

Figura 8. Resistência à tração por compressão diametral dos briquetes e força máxima; $\mathrm{BE}$ : briquetes de serragem de eucalipto; BM: briquetes de resíduos moídos do milho; $\mathrm{BCC}$ : briquetes de casca de café moída. Médias seguidas pela mesma letra não diferem a 5\% de significância pelo Teste de Tukey.

Já os briquetes de serragem de eucalipto e dos resíduos da colheita do milho apresentaram estatisticamente a menor resistência à tração por compressão diametral e força máxima média de 2,94 kN. Contudo, esses resultados não desclassificam esses resíduos para a produção de energia, apenas indicam a necessidade de mais pesquisas relacionadas à briquetagem desses materiais.

\section{Conclusões}

Abiomassa proveniente dos resíduos do processamento dos grãos de café apresentou maior potencialidade de utilização energética para produção de briquetes, pois obteve os maiores valores de densidade energética e resistência à tração por compressão diametral, além de apresentar maior estabilidade após a compactação para todas as variáveis analisadas.

Os resíduos da colheita do milho e a serragem de eucalipto apresentaram maior aumento percentual da densidade aparente e energética em relação à casca de café, considerando-se a biomassa antes e após a compactação. Esse resultado demonstra o potencial de utilização desses resíduos para o processo de briquetagem.

Recomendam-se mais estudos relacionados à briquetagem da serragem de eucalipto e dos resíduos da colheita do milho, visando ao controle da instabilidade dimensional desses briquetes.

\section{Referências}

AMERICAN SOCIETY FOR TESTINT AND MATERIALS. D1762-84: standard test method for chemical analysis of wood charcoal. Phyladelphia, 2001. 2 p.

ASSOCIAÇÃO BRASILEIRA DE NORMAS TÉCNICAS. NBR 7222: argamassa e concreto: determinação da resistência à tração por compressão diametral de corpos-de-prova cilíndricos: método de ensaio. Rio de Janeiro, 1994. 3 p.

ASSOCIAÇÃO BRASILEIRA DE NORMAS TÉCNICAS. NBR 8633: carvão vegetal: determinação do poder calorífico: método de ensaio. Rio de Janeiro, 1984. 13 p.

BACK, E. L.; SALMÉN, N. L. Glass transition of wood components hold implications for molding and pulping processes. Tappi Journal, Norgross, EUA, v. 65, n. 7, p. 107-110, 1982.

BOTREL, M. C. G.; TRUGILHO, P. F.; ROSADO, S. C. S.; SILVA, J. R. M. Melhoramento genético das propriedades do carvão vegetal de Eucalyptus. Revista Árvore, Viçosa, MG, v. 31, n. 3, p. 391-398, 2007.

BRAND, M. A. Energia da biomassa florestal. Rio de Janeiro: Interciência, 2010. 114 p. 
EMPRESA DE PESQUISA ENERGÉTICA. Balanço energético nacional 2010: ano base 2009. Rio de Janeiro, 2010. 276 p. Disponível em: <https://ben.epe.gov.br/downloads/Relatorio_ Final_BEN_2010.pdf $>$. Acesso em: 15 abr. 2011.

CHIN, O. C.; SIDDIQUI, K. M. Characteristics of some biomass briquettes prepared under modest die pressures. Biomass and Bioenergy, Oxford, GB, v. 18, n. 3, p. 223-228, 2000.

COUTO, L. C.; COUTO, L.; WATZLAWICK; L. F.; CÂMARA, D. Vias de valorização energética da biomassa. Biomassa \& Energia, Viçosa, MG, v. 1, n. 1, p. 71-92, 2004.

DEMIRBAS, A. Physical properties of briquettes from waste paper and wheat straw mixtures. Energy Conversion \& Management, Oxford, GB, v. 40, n. 4, p. 437-445, 1999.

FRIEDL, A.; PADOUVAS, E.; ROTTER, H.; VARMUZA, K. Prediction of heating values of biomass fuel from elemental composition. Analytica Chimica Acta, Amsterdam, NL, v. 544, n. 1-2, p. 191-198, 2005.

FURTADO, T. S.; VALIN, M.; BRAND, M. A.; BELLOTE, A. F. $\mathrm{J}$. Variáveis do processo de briquetagem e qualidade de briquetes de biomassa florestal. Pesquisa Florestal Brasileira, Colombo, v. 30, n. 62, p. 101-106, 2010. doi: 10.4336/2010.pfb.30.62.101.

GRANADA, E.; LÓPEZ GONZÁLEZ, L. M.; MÍGUEZ, J. L.; MORAN, J. Fuel lignocellulosic briquettes, die design and products study. Renewable Energy, Oxford, GB, v. 27, n. 4, p. 561-573, 2002.

IWAKIRI, S.; ALBUQUERQUE, C. E. C.; PRATA, J. G.; COSTA, A. C. B. Utilização de Eucalyptus grandis e Eucalyptus dunii para a produção de partículas orientadas - OSB. Ciência Florestal, Santa Maria, RS, v. 18, n. 2, p. 265-270, 2008.

KALIYAN, N.; MOREY, R. V. Factors affecting strength and durability of densified biomass products. Biomass and Bioenergy, Oxford, GB, v. 33, n. 3, p. 337-359, 2009.

LIMA, E. A.; SILVA, H. D.; LAVORANTI, O. J. Caracterização dendroenergética de árvores de Eucalyptus benthamii. Pesquisa Florestal Brasileira, Colombo, v. 31, n. 65, p. 09-17, 2011. doi: 10.4336/2010.pfb.31.65.09.

NOGUEIRA, L. A. H.; LORA, E. E. S. Dendroenergia: fundamentos e aplicações. 2. ed. Rio de Janeiro: Interciência, 2003. 199 p.
PARIKH, J.; CHANNIWALA, S. A.; GHOSAL, G. K. A correlation for calculating HHV from proximate analysis of solid fuels. Fuel, London, GB, v. 84, n. 5, p. 487-494, 2005.

PAULA, L. E. R.; TRUGILHO, P. F.; REZENDE, R. N.; ASSIS, C. O.; BALIZA, A. E. R. Produção e avaliação de briquetes de resíduos lignocelulósicos. Pesquisa Florestal Brasileira, Colombo, v. 31, n. 66, p. 103-112, 2011a. doi: 10.4336/2011. pfb.31.66.103.

PAULA, L. E. R.; TRUGILHO, P. F.; NAPOLI, A.; BIANCHI, M. L. Characterization of residues from plant biomass for use in energy generation. Cerne, Lavras, MG, v. 17, n. 2, p. 237-246, 2011 b.

PIMENTEL-GOMES. Curso de estatística experimental. 15. ed. Piracicaba, SP: FEALQ, 2009. 451 p.

PROTÁSIO, T. P.; BUFALINO, L.; TONOLI, G. H. D.; COUTO, A. M.; TRUGILHO, P. F.; GUIMARÃES JÚNIOR, M. Relação entre o poder calorífico superior e os componentes elementares e minerais da biomassa vegetal. Pesquisa Florestal Brasileira, Colombo, v. 31, n. 66, p. 122-133, 2011. doi: 10.4336/2011. pfb.31.66.113.

QUIRINO, W. F.; VALE, A. T.; ANDRADE, A. P. A.; ABREU, V. L.; AZEVEDO, A. C. S. Poder calorífico da madeira e de resíduos lignocelulósicos. Biomassa \& Energia, Viçosa, MG, v. 1, n. 2, p. 173-182, 2004.

QUIRINO, W. F.; BRITO, J. O. Briquetagem de resíduos lignocelulósicos. Brasília, DF: LPF/IBAMA, 1991. 18 p. (Série técnica, 13).

RABIER, F.; TEMMERMAN, M.; BÖHM, T.; HARTMANN, H.; JENSEN, P. D.; RATHBAUER, J.; CARRASCO, J.; FERNÁNDEZ, M. Particle density determination of pellets and briquettes. Biomass and Bioenergy, Oxford, GB, v. 30, n.11, p. 954-963, 2006.

RUBIO, B.; IZQUIERDO, M. T.; SEGURA, E. Effect of binder addition on the mechanical and physicochemical properties of low rank coal char briquettes. Carbon, Nova York, v. 37, n. 11, p. 1833-1841, 1999.

TRUGILHO, P. F.; LIMA, J. T.; MORI, F. A; LINO, A. L. Avaliação de clones de Eucalyptus para a produção de carvão vegetal. Cerne, Lavras, MG, v. 7, n. 2, p. 104-114, 2001.

TRUGILHO, P. F.; SILVA, J. R. M.; MORI, F. A.; LIMA, J. T.; MENDES, L. M.; MENDES, L. F. B. Rendimentos e características do carvão vegetal em função da posição radial de amostragem em clones de Eucalyptus. Cerne, Lavras, MG, v. 11, n. 2, p. 178-186, 2005. 
